\title{
DERIVATION-HOMOMORPHISM FUNCTIONAL INEQUALITIES
}

\section{CHOONKIL PARK}

Abstract. In this paper, we introduce and solve the following additive-additive $(s, t)$-functional inequality

$$
\begin{aligned}
& \|g(x+y)-g(x)-g(y)\|+\|h(x+y)+h(x-y)-2 h(x)\| \\
& \leqslant\left\|s\left(2 g\left(\frac{x+y}{2}\right)-g(x)-g(y)\right)\right\|+\left\|t\left(2 h\left(\frac{x+y}{2}\right)+2 h\left(\frac{x-y}{2}\right)-2 h(x)\right)\right\|,
\end{aligned}
$$

where $s$ and $t$ are fixed nonzero complex numbers with $|s|<1$ and $|t|<1$. Using the direct method and the fixed point method, we prove the Hyers-Ulam stability of derivation-homomorphisms in complex Banach algebras, associated to the additive-additive $(s, t)$-functional inequality (1) and the following functional inequality

$$
\|g(x y)-g(x) y-x g(y)\|+\|h(x y)-h(x) h(y)\| \leqslant \varphi(x, y) .
$$

Mathematics subject classification (2010): Primary 47B47, 17B40, 39B72, 39B62, $39 \mathrm{~B} 52$.

Keywords and phrases: Hyers-Ulam stability, direct method, fixed point method, additive-additive $(s, t)$-functional inequality, derivation in Banach algebra, homomorphism in Banach algebra.

\section{REFERENCES}

[1] T. AOKI, On the stability of the linear transformation in Banach spaces, J. Math. Soc. Japan 2 (1950), 64-66.

[2] J. BAE AND W. PARK, Approximate bi-homomorphisms and bi-derivations in $C^{*}$-ternary algebras, Bull. Korean Math. Soc. 47 (2010), 195-209.

[3] L. CĂDARIU, V. RADU, Fixed points and the stability of Jensen's functional equation, J. Inequal. Pure Appl. Math. 4, no. 1, Art. ID 4 (2003).

[4] L. CĂDARIU, V. RADU, On the stability of the Cauchy functional equation: a fixed point approach, Grazer Math. Ber. 346 (2004), 43-52.

[5] L. CĂDARIU, V. RADU, Fixed point methods for the generalized stability of functional equations in a single variable, Fixed Point Theory Appl. 2008, Art. ID 749392 (2008).

[6] J. Diaz, B. MARGolis, A fixed point theorem of the alternative for contractions on a generalized complete metric space, Bull. Am. Math. Soc. 74 (1968), 305-309.

[7] Y. Ding, T.-Z. XU, Approximate solution of generalized inhomogeneous radical quadratic functional equations in 2-Banach spaces, J. Inequal. Appl. 2019, 2019:31, 13 pp.

[8] A. Ebadian, S. Zolfagfhari, S. Ostadbashi, C. Park, Approximation on the reciprocal functional equation in several variables in matrix non-Archimedean random normed spaces, Adv. Difference Equ. 2015, 2015:314, 13 pp.

[9] I. EL-FASSI, Generalized hyperstability of a Drygas functional equation on a restricted domain using Brzdek's fixed point theorem, J. Fixed Point Theory Appl. 19 (2017), 2529-2540.

[10] W. FeChner, Stability of a functional inequalities associated with the Jordan-von Neumann functional equation, Aequationes Math. 71 (2006), 149-161.

[11] P. GǍVRUTA, A generalization of the Hyers-Ulam-Rassias stability of approximately additive mappings, J. Math. Anal. Appl. 184 (1994), 431-436.

[12] A. GiláNYI, Eine zur Parallelogrammgleichung äquivalente Ungleichung, Aequationes Math. 62 (2001), 303-309. 
[13] A. GilánYi, On a problem by K. Nikodem, Math. Inequal. Appl. 5 (2002), 707-710.

[14] D.H. HYERS, On the stability of the linear functional equation, Proc. Nat. Acad. Sci. U.S.A. 27 (1941), 222-224.

[15] G. IsAC, TH. M. RAssias, Stability of $\psi$-additive mappings: Applications to nonlinear analysis, Int. J. Math. Math. Sci. 19 (1996), 219-228.

[16] D. Mineţ, V. RADU, On the stability of the additive Cauchy functional equation in random normed spaces, J. Math. Anal. Appl. 343 (2008), 567-572.

[17] I. NikoufaR, Jordan $(\theta, \phi)$-derivations on Hilbert $C^{*}$-modules, Indag. Math. 26 (2015), 421-430.

[18] C. PARK, Homomorphisms between Poisson JC* -algebras, Bull. Braz. Math. Soc. 36 (2005), 79-97.

[19] C. PARK, Additive $\rho$-functional inequalities and equations, J. Math. Inequal. 9 (2015), 17-26.

[20] C. PARK, Additive $\rho$-functional inequalities in non-Archimedean normed spaces, J. Math. Inequal. 9 (2015), 397-407.

[21] C. PARK, Fixed point method for set-valued functional equations, J. Fixed Point Theory Appl. 19 (2017), 2297-2308.

[22] V. RADU, The fixed point alternative and the stability of functional equations, Fixed Point Theory 4 (2003), 91-96.

[23] TH. M. RASSiAS, On the stability of the linear mapping in Banach spaces, Proc. Am. Math. Soc. 72 (1978), 297-300.

[24] J. RÄTZ, On inequalities associated with the Jordan-von Neumann functional equation, Aequationes Math. 66 (2003), 191-200.

[25] S. M. Ulam, A Collection of the Mathematical Problems, Interscience Publ. New York, 1960. 